\title{
Thermal Decomposition of Multiply Charged T-Rich Oligonucleotide Anions in the Gas Phase. Influence of Internal Solvation on the Arrhenius Parameters for Neutral Base Loss
}

\author{
Rambod Daneshfar and John S. Klassen \\ Department of Chemistry, University of Alberta, Edmonton, Alberta, Canada
}

\begin{abstract}
Arrhenius activation parameters $\left(E_{a}, A\right)$ for the loss of neutral nucleobases from a series of T-rich, doubly and triply deprotonated 15- and 20-mer oligodeoxynucleotides (ODN) containing a single reactive base $(X=A$ or $C)$ with the sequence, $\mathrm{XT}_{14}, \mathrm{XT}_{19}$ and $\mathrm{T}_{19} \mathrm{X}$, have been determined using the blackbody infrared radiative dissociation technique. The A-containing anions are significantly more reactive ( $\geq 3000$ times) than the C-containing ions over the temperature range investigated. Importantly, the Arrhenius parameters for the loss of $\mathrm{AH}$ exhibit a strong dependence on size of the ODN and, to some extent, the charge state; the Arrhenius parameters increase with size and charge $\left(E_{a}=29-39 \mathrm{kcal}\right.$ $\left.\mathrm{mol}^{-1}, A=10^{15}-10^{20} \mathrm{~s}^{-1}\right)$. In contrast, the parameters for the loss of $\mathrm{CH}$ are much less sensitive to size $\left(E_{a}=35-39 \mathrm{kcal} \mathrm{mol}^{-1}, A=10^{14}-10^{17} \mathrm{~s}^{-1}\right)$. The results are consistent with a greater contribution from the internal solvation of the reactive base to the Arrhenius parameters for the loss of A, compared with C, from the 15- and 20-mers. To further probe differences in internal solvation of $\mathrm{A}$ and $\mathrm{C}$, hydrogen/deuterium exchange was carried out on $\mathrm{AT}_{19}^{-3}, \mathrm{~T}_{19} \mathrm{~A}^{-3}, \mathrm{CT}_{19}^{-3}$ and $\mathrm{T}_{19} \mathrm{C}^{-3}$ using $\mathrm{D}_{2} \mathrm{O}$ as the exchange reagent. However, the $\mathrm{H} / \mathrm{D}$ exchange results did not reveal any differences in internal solvation within the ODN anions. Arrhenius parameters for the dissociation of noncovalent complexes of $\mathrm{T}_{20}^{-3}$ and the neutral nucleobase $\mathrm{AH}$ or $\mathrm{CH}$ have also been determined. Differences in the parameters indicate differences in the nature of the intermolecular interactions. It is proposed that neutral A-T interactions (i.e., base-base), which originate in solution, dominate in the case of $\left(\mathrm{T}_{20}+\mathrm{AH}\right)^{-3}$, while charge solvation, involving $\mathrm{CH}$ and a deprotonated phosphate group, is present for $\left(\mathrm{T}_{20}+\mathrm{CH}\right)^{-3}$. (J Am Soc Mass Spectrom 2006, 17, 1229-1238) @ 2006 American Society for Mass Spectrometry
\end{abstract}

$\mathrm{M}$ ass spectrometry (MS), combined with electrospray ionization (ES) or matrix-assisted laser desorption/ionization (MALDI), is an important tool for sequencing DNA and RNA oligonucleotides. Direct oligonucleotide sequencing is normally carried out using tandem MS (i.e., MS/MS) whereby the gaseous oligonucleotide ion of interest is first isolated using one stage of MS, then subjected to collisional or radiative heating (activation) to induce fragmentation, followed by a second stage of MS to analyze the mass of the fragment ions. Sequence information is deduced from the mass difference for sequential fragment ions that share the same general structure, vide infra [1]. Because sequence is determined from mass differences, the tandem MS approach is equally applicable to oligonucleotides containing natural, unnatural, or modified residues.

Published online June 16, 2006

Address reprint requests to Dr. J. S. Klassen, Department of Chemistry, University of Alberta, Edmonton, Alberta T6G 2G2, Canada. E-mail: john.klassen@ualberta.ca
While tandem MS is now routinely used to deduce sequence information for oligonucleotides, the mechanisms of fragmentation of these biopolymers in the gas phase are not fully understood. Studies of the fragmentation of gaseous multiply deprotonated oligodeoxynucleotide (ODN) ions, the focus of the present study, have shown that dissociation proceeds initially by the loss of a nucleobase, either in its neutral or deprotonated form, with subsequent cleavage of the adjacent $3^{\prime} \mathrm{C}-\mathrm{O}$ phosphodiester bond of the deoxyribose to produce complementary ions, referred to as [a-Base] and $\mathrm{w}$ ions according to the nomenclature proposed by McLuckey et al. [2]. The tendency for bases to be lost in their neutral or deprotonated form depends on the charge state of the ODN, with higher charge states favoring the loss of deprotonated base. Several mechanisms have been proposed for the loss of nucleobases from ODN anions and these have been recently reviewed by Gross and coworkers [3,4]. The different mechanisms fall into two categories, those in which the nucleobase is lost in its deprotonated form, which may be followed by proton abstraction from the ODN to 
yield the neutral base, and those in which proton transfer from the ODN to the nucleobase occurs before or in concert with cleavage of the glycosidic bond, such that the base is lost directly as a neutral. It has been suggested that the different mechanisms might be distinguished based on the relative reactivity of the four DNA bases, adenine (A), guanine $(\mathrm{G})$, cytosine $(\mathrm{C})$, and thymine $(\mathrm{T})$. Specifically, if the base is protonated before cleavage of the glycosidic bond, the relative reactivity of the bases might be expected to follow the trend in gas-phase basicities or proton affinities of the nucleobase. If the base is initially lost in its deprotonated form, the relative reactivity is expected to follow the trend in gas-phase acidities. Underlying these arguments are the important assumptions that the strength of the N-glycosidic bonds for the four bases are similar and that cleavage of the glycosidic bond represents the rate-limiting step for base loss. The loss of the nucleobases in their deprotonated form generally follows the trend, $\mathrm{A}^{-}>\mathrm{T}^{-}>\mathrm{G}^{-} \approx \mathrm{C}^{-}$, although somewhat different trends have also been reported [5]. Interestingly, the trend in reactivity does not strictly follow the trend in gas-phase acidity or deprotonation enthalpy for the nucleobases, $A \approx G \approx T<C$ [6]. Numerous studies of neutral base loss from ODN anions have been reported [3-5, 7-17]. However, no general trend in the relative kinetic reactivity of the bases has been identified. Instead, the relative reactivity seems to be influenced by a number of factors, notably the size, sequence and charge state of the ODN as well the internal energy of the ions.

The first quantitative study of the kinetics and energetics for the loss of neutral nucleobases from gaseous ODN anions was carried out by Williams and coworkers [14]. Using the blackbody infrared radiative dissociation (BIRD) technique, they determined Arrhenius activation energies $\left(E_{a}\right)$ and pre-exponential factors $(A)$ for the loss of $\mathrm{AH}, \mathrm{CH}$, and $\mathrm{GH}$ from some doubly deprotonated 7-mers. The loss of TH was not observed at reaction temperatures of up to $210^{\circ} \mathrm{C}$. Because all of the ODNs investigated contained multiple reactive bases, the reported Arrhenius parameters were average values, reflecting the loss of base from multiple positions. The first quantitative study of the Arrhenius parameters for the loss of individual nucleobases was recently reported by our laboratory [17]. BIRD was performed on a series of doubly deprotonated T-rich ODN anions of the type $\mathrm{XT}_{9}, \mathrm{~T}_{9} \mathrm{X}$ and $\mathrm{T}_{5} \mathrm{XT}_{4}$, where $\mathrm{X}=$ $\mathrm{A}, \mathrm{G}$ or $\mathrm{C}$. Because the $\mathrm{T}$ residues are unreactive, it was possible to quantify the Arrhenius parameters for the loss of the individual $\mathrm{AH}, \mathrm{GH}$ and $\mathrm{CH}$ from the $5^{\prime}$ and $3^{\prime}$ termini, and the internal position of the 10-mers. The trend in the dissociation $E_{a}$ values was shown to be sensitive to the position of the nucleobase: $C>G>A$ ( $5^{\prime}$ and $3^{\prime}$ termini), $\mathrm{C}>\mathrm{A}>\mathrm{G}$ (internal position). Importantly, it was noted that the trends in $E_{a}$ values do not simply follow trends in either gas-phase deprotonation enthalpies or proton affinities, and by themselves do not provide insight into whether the reactive nucleobase is initially protonated before cleavage of the glycosidic bond or whether the base is initially lost in its deprotonated form. It was suggested that the Arrhenius parameters for base loss were influenced by noncovalent intramolecular interactions involving the reactive nucleobase. Based on the trends in $E_{a}$ and $A$ values, it was further suggested that, independent of the position within the 10-mer, C participates in greater internal solvation than do A or G.

An interesting question, not addressed in the earlier BIRD study [17], is how size and charge state of ODN anions influence the degree of internal solvation and, correspondingly, the kinetics and energetics of neutral base loss. The present study seeks to answer this question and to further test the hypothesis that there are inherent differences in the intramolecular solvation of A, G, and C within the T-rich ODN anions. Timeresolved BIRD experiments have been performed on doubly and triply deprotonated T-rich 15- and 20-mer anions containing one reactive base $(X)$ at the $5^{\prime}$ or $3^{\prime}$ termini, $\mathrm{XT}_{14}, \mathrm{XT}_{19}$, and $\mathrm{T}_{19} \mathrm{X}$, where $\mathrm{X}=\mathrm{A}$ or $\mathrm{C}$. From the temperature dependence of the dissociation rate constants for the loss of neutral A or C, Arrhenius activation parameters have been determined. Insights into the influence of base solvation and $\mathrm{N}$-glycosidic bond cleavage on the reaction dynamics and energetics for base loss were deduced from a comparison of the Arrhenius parameters determined for the 15- and 20mers, as well as values previously reported for the $\mathrm{XT}_{9}$ and $\mathrm{T}_{9} \mathrm{X} 10$-mers. To further explore the possible differences in nucleobase solvation within the ODN anions, gas-phase hydrogen/deuterium exchange has been performed on the triply deprotonated A- and C-containing 20-mers. Additionally, BIRD experiments were carried out on triply deprotonated noncovalent complexes of $\mathrm{T}_{20}$ with neutral $\mathrm{AH}$ or $\mathrm{CH}$ to establish whether, when bound noncovalently to ODN anions, the nucleobases experience differences in intermolecular solvation.

\section{Experimental}

All experiments were performed on an ApexII Fouriertransform ion cyclotron resonance (FT-ICR) mass spectrometer (Bruker, Billerica, MA) equipped with a 4.7 or 9.4 $\mathrm{T}$ superconducting magnet and an external nanoelectrospray (nanoES) ion source. The ODNs were purchased from ACGT Corp. (Toronto, Canada) and used without further purification. The free nucleobases, $\mathrm{AH}$ and $\mathrm{CH}$, were purchased from Sigma-Aldrich Co. (Oakville, Canada). To produce the gaseous ODN anions, nanoES was performed on $1: 1 \mathrm{H}_{2} \mathrm{O} / \mathrm{CH}_{3} \mathrm{CN}$ solutions containing $200 \mu \mathrm{M}$ ODN. To produce the noncovalent complexes of $\mathrm{T}_{20}$ with $\mathrm{CH}$ or $\mathrm{AH}$, nanoES was performed on 1:1 $\mathrm{H}_{2} \mathrm{O} / \mathrm{CH}_{3} \mathrm{CN}$ solutions containing 50 $\mu \mathrm{M} \mathrm{T}_{20}$ and $50 \mu \mathrm{M}$ AH or $\mathrm{CH}$. NanoES tips were pulled from aluminosilicate tubes ( $1 \mathrm{~mm}$ o.d., $0.68 \mathrm{~mm}$ i.d.) using a P-2000 micropipette puller (Sutter Instruments, Novato, CA). A platinum (Pt) wire, inserted into the open end of the nanoES tip, was used to apply a 
potential of approximately $-800 \mathrm{~V}$ to the nanoES solution. The tip was positioned 1 to $2 \mathrm{~mm}$ from a stainless steel sampling capillary using a microelectrode holder. The solution flow rate typically ranged from 60 to 100 $\mathrm{nL} / \mathrm{min}$ depending on the diameter of the nanoES tip and the nanoES potential.

The droplets and gaseous ions produced by nanoES were introduced into the mass spectrometer through a heated stainless steel capillary (i.d. $0.42 \mathrm{~mm}$ ) maintained at $62{ }^{\circ} \mathrm{C}$. The ion/gas jet sampled by the capillary $(-48 \mathrm{~V})$ was transmitted through a skimmer $(-1 \mathrm{~V})$ and stored electrodynamically in an rf hexapole. Ions were accumulated in the hexapole for between 1 and $5 \mathrm{~s}$, depending on the ion's size and the desired charge state, subsequently ejected and injected at $\sim 2700 \mathrm{~V}$ into the bore of the superconducting magnet, decelerated, and introduced into the ion cell. The trapping plates of the cell were maintained at a constant potential of $-2 \mathrm{~V}$ throughout the experiments. The typical base pressure for the instrument was $\sim 5 \times 10^{-10}$ mbar. For the BIRD experiments, the temperature of the ion cell was controlled with two external flexible heating blankets placed around the vacuum tube in the vicinity of the ion cell [18]. Hydrogen/deuterium (H/D) exchange experiments were performed by introducing $\mathrm{D}_{2} \mathrm{O}$, at a static pressure (uncorrected) of $7 \times 10^{-10} \mathrm{mbar}$, into the vacuum chamber. The ion cell temperature and, correspondingly, the temperature of the deuterating agent inside the cell was $\sim 22{ }^{\circ} \mathrm{C}$. The $\mathrm{H} / \mathrm{D}$ exchange experiments were performed exclusively at a magnetic field strength of $9.4 \mathrm{~T}$. Mass spectra were acquired by an SGI R5000 computer running the Bruker Daltonics XMASS software, version 5.0.10. Isolation of the reactant ions for the BIRD and H/D exchange experiments was achieved using rf frequency excitation. The isolated ions were stored inside the heated cell for varying reaction times before excitation and detection. For the BIRD experiments the time-domain signal consisted of the sum of 20 transients containing $128 \mathrm{~K}$ data points per transient, while for H/D exchange experiments, with $512 \mathrm{~K}$ data points, the time domain signal was subjected to one zero-fill before Fourier transformation.

\section{Results and Discussion}

\section{Dissociation Pathways of ODN Anions}

NanoES of 1:1 $\mathrm{H}_{2} \mathrm{O}: \mathrm{CH}_{3} \mathrm{CN}$ solutions containing $\sim 200$ $\mu \mathrm{M}$ ODN $\left(\mathrm{XT}_{14}, \mathrm{XT}_{19}\right.$, or $\mathrm{T}_{19} \mathrm{X}$, where $\left.\mathrm{X}=\mathrm{A}, \mathrm{C}\right)$ produced predominantly the triply deprotonated ODN ions, $(\mathrm{M}-3 \mathrm{H})^{-3} \equiv \mathrm{M}^{-3}$, Figure 1 . In certain cases, the $\mathrm{M}^{-2}, \mathrm{M}^{-4}$ and $\mathrm{M}^{-5}$ ions were also present at low abundance. Additionally, adducts corresponding to the attachment of alkali metals or phosphoric or acetic acid to the ODN anions were also sometimes observed.

BIRD was performed on the $\mathrm{M}^{-\mathrm{n}}$ ions, where $n=2$ and 3, at temperatures ranging from 80 to $190^{\circ} \mathrm{C}$. Representative BIRD spectra for each of the $\mathrm{M}^{-\mathrm{n}}$ ions investigated are shown in Figure 2. The dissociation
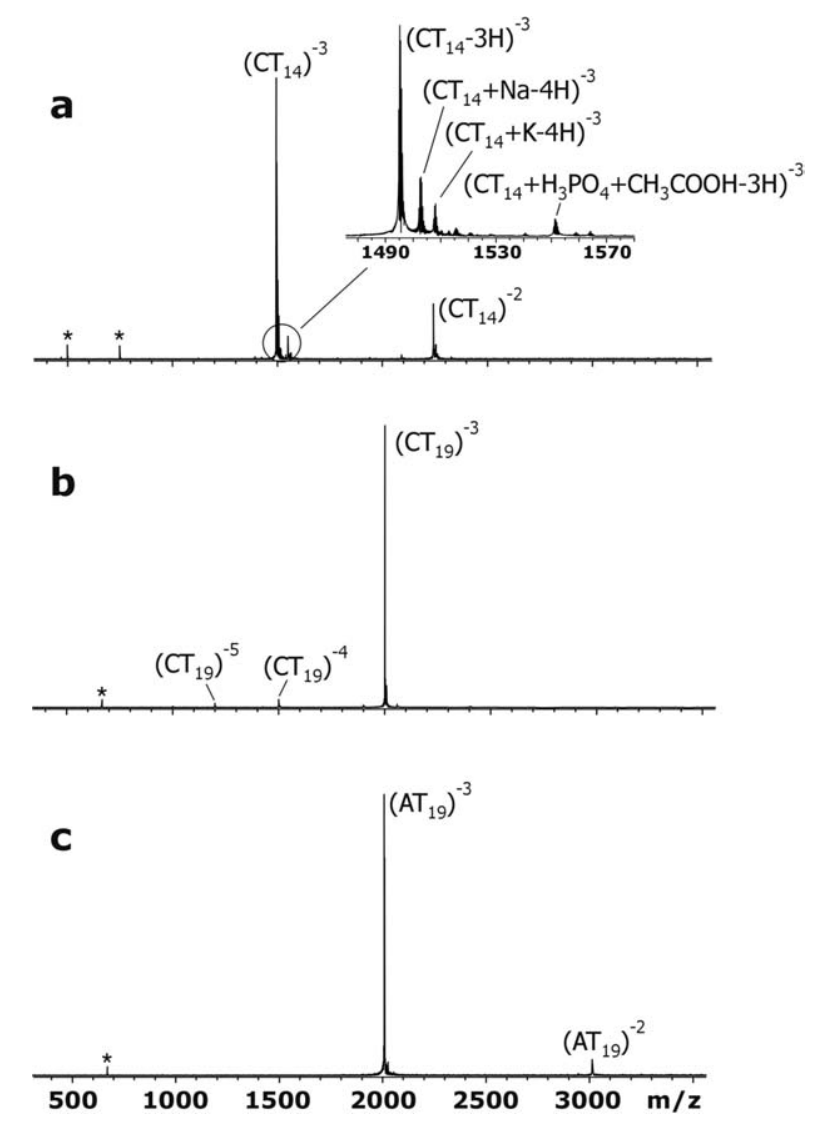

Figure 1. NanoES mass spectra of $1: 1 \mathrm{H}_{2} \mathrm{O}: \mathrm{CH} 3 \mathrm{CN}$ solutions containing $200 \mu \mathrm{M}$ (a) $\mathrm{CT}_{14}$, (b) $\mathrm{CT}_{19}$, and (c) $\mathrm{AT}_{19}$. The asterisk indicates a harmonic of the precursor ion [19].

pathways observed for the 15- and 20-mers are consistent with the pathways previously identified for the dissociation of the corresponding $\mathrm{XT}_{0}^{-2}$ and $\mathrm{T}_{9} \mathrm{X}^{-2}$ ions. Dissociation of the doubly and triply charged $\mathrm{AT}_{\mathrm{m}}^{-\mathrm{n}}$ ions, where $\mathrm{m}=14$ or 19 , yielded product ions corresponding to the loss of neutral base, $\left(\mathrm{AT}_{\mathrm{m}}-\mathrm{AH}\right)^{-\mathrm{n}}$, and cleavage of the sugar $3^{\prime} \mathrm{C}-\mathrm{O}$ bond, leading to $\mathrm{w}_{14}^{-\mathrm{n}}$ and $\mathrm{w}_{19}^{-\mathrm{n}}$ ions for $\mathrm{AT}_{14}^{-\mathrm{n}}$ and $\mathrm{AT}_{19}^{-\mathrm{n}}$, respectively (eq 1a). Dissociation of the doubly and triply charged $\mathrm{T}_{19} \mathrm{~A}^{-\mathrm{n}}$ ions resulted in the formation of $\left(\mathrm{T}_{19} \mathrm{~A}-\mathrm{AH}\right)^{-\mathrm{n}}$ and $\left(\mathrm{T}_{19} \mathrm{~A}-\mathrm{AH}-\mathrm{H}_{2} \mathrm{O}\right)^{-\mathrm{n}}$ ions (eq $\left.1 \mathrm{~b}\right)$. For the C-containing ions, only the secondary fragment ions, $\mathrm{w}_{\mathrm{m}}^{-\mathrm{n}}$ and $\left(\mathrm{T}_{\mathrm{m}} \mathrm{C}-\mathrm{CH}-\mathrm{H}_{2} \mathrm{O}\right)^{-\mathrm{n}}$, were present in the BIRD spectra. It was shown previously by double resonance experiments that the loss of neutral $\mathrm{CH}$ is the only primary dissociation channel for the $\mathrm{C}$-containing $\mathrm{T}$ rich 10-mers, and that the absence of the $\left(\mathrm{XT}_{\mathrm{m}}-\mathrm{XH}\right)^{-\mathrm{n}}$ and $\left(\mathrm{T}_{\mathrm{m}} \mathrm{X}-\mathrm{XH}\right)^{-\mathrm{n}}$ ions in the BIRD spectra is attributed to the slow dissociation kinetics for the loss of $\mathrm{CH}$ compared with the secondary dissociation processes [17]. There was no evidence for the loss of neutral $T$ in any of the BIRD spectra, consistent with previous BIRD studies of deprotonated ODN anions [14, 17].

$$
\begin{aligned}
& \mathrm{XT}_{\mathrm{m}}^{-\mathrm{n}} \rightarrow\left(\mathrm{XT}_{\mathrm{m}}-\mathrm{XH}\right)^{-\mathrm{n}} \rightarrow \mathrm{W}_{\mathrm{m}}^{-\mathrm{n}} \\
& \mathrm{T}_{\mathrm{m}} \mathrm{X}^{-\mathrm{n}} \rightarrow\left(\mathrm{T}_{\mathrm{m}} \mathrm{X}-\mathrm{XH}\right)^{-\mathrm{n}} \rightarrow\left(\mathrm{T}_{\mathrm{m}} \mathrm{X}-\mathrm{XH}-\mathrm{H}_{2} \mathrm{O}\right)^{-\mathrm{n}}
\end{aligned}
$$



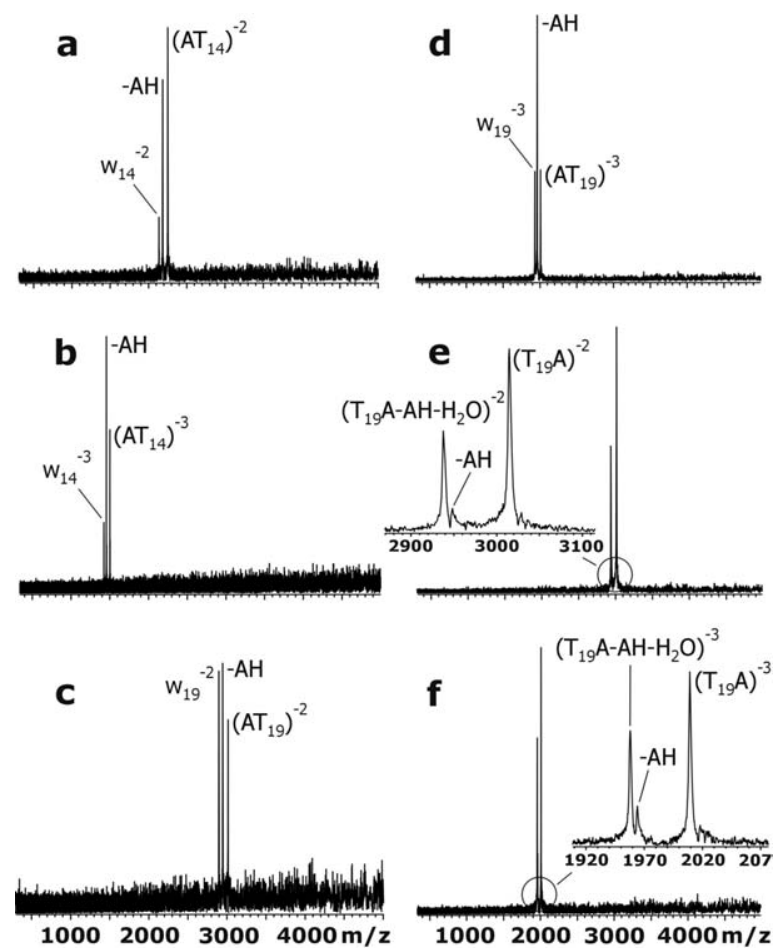

$1000200030004000 \mathrm{~m} / \mathrm{z}$
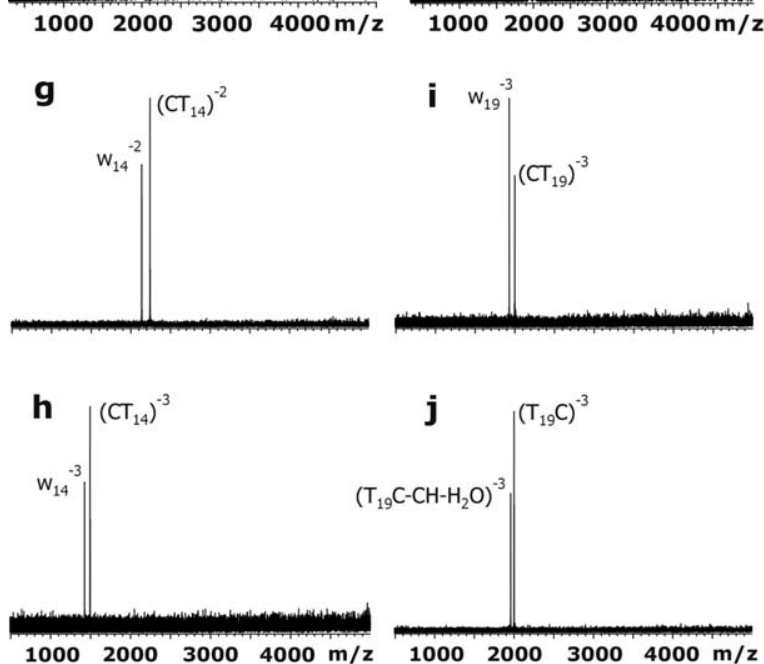

Figure 2. Blackbody infrared radiative dissociation spectra of doubly and triply deprotonated ODN anions (a) $\left(\mathrm{AT}_{14}\right)^{-2}$ at $98^{\circ} \mathrm{C}$ and a reaction delay of $30 \mathrm{~s},(\mathbf{b})\left(\mathrm{AT}_{14}\right)^{-3}\left(100{ }^{\circ} \mathrm{C}, 20 \mathrm{~s}\right),(\mathbf{c})\left(\mathrm{AT}_{19}\right)^{-2}$ $\left(121.5^{\circ} \mathrm{C}, 18 \mathrm{~s}\right),(\mathbf{d})\left(\mathrm{AT}_{19}\right)^{-3}\left(135.5^{\circ} \mathrm{C}, 2 \mathrm{~s}\right),(\mathbf{e})\left(\mathrm{T}_{19} \mathrm{~A}\right)^{-2}\left(121^{\circ} \mathrm{C}\right.$, $6 \mathrm{~s}),(\mathbf{f})\left(\mathrm{T}_{19} \mathrm{~A}\right)^{-3}\left(134^{\circ} \mathrm{C}, 1.25 \mathrm{~s}\right),(\mathrm{g})\left(\mathrm{CT}_{14}\right)^{-2}\left(164.5^{\circ} \mathrm{C}, 100 \mathrm{~s}\right),(\mathbf{h})$ $(\mathrm{CT} 14)^{-3}\left(164.5^{\circ} \mathrm{C}, 100 \mathrm{~s}\right),(\mathrm{i})\left(\mathrm{CT}_{19}\right)^{-3}\left(167.5^{\circ} \mathrm{C}, 110 \mathrm{~s}\right)$, and $(\mathrm{j})$ $\left(\mathrm{T}_{19} \mathrm{C}\right)^{-3}\left(166^{\circ} \mathrm{C}, 75 \mathrm{~s}\right)$.

\section{Dissociation Kinetics and Arrhenius Parameters for ODN Anions}

The temperature-dependent first-order rate constants ( $k$ ) for the loss of neutral nucleobase were determined from the change in the natural log of the normalized intensity (abundance) of the ODN reactant ions $\left(I_{R, n o r m}\right)$ with reaction time (eq 2$). I_{R, n o r m}$ was calculated using eq 3 , where $I_{R}$ is the abundance of the reactant ion and $\Sigma I_{P}$ is the sum of the abundance of all product ions, including those produced by secondary reactions. Be- cause of difficulties in accurately quantifying the low abundance isotopic peaks, within their respective isotope envelope for the reactant and product ions, due to poor signal-to-noise ratios, $I_{R, n o r m}$ was calculated using only the most abundant isotopic ion for the reactant and product ions. As noted previously [17], this approach leads to $I_{R, n o r m}$ values that are within $15 \%$ of the values obtained when all isotope peaks are considered. Illustrative kinetic plots obtained for $\left(\mathrm{CT}_{14}\right)^{-3},\left(\mathrm{CT}_{19}\right)^{-3}$, and $\left(\mathrm{AT}_{19}\right)^{-3}$, at five different temperatures are shown in Figure 3. The plots are linear and exhibit near zero intercepts, as expected for simple first-order reactions. Plots of similar quality were obtained for all of the ODN anions investigated. The dissociation rate constant was determined from the slope of a linear least-squares fit of the kinetic data obtained at each temperature investigated.

$$
\ln \left(I_{R, n o r m, t}\right)=-k t
$$
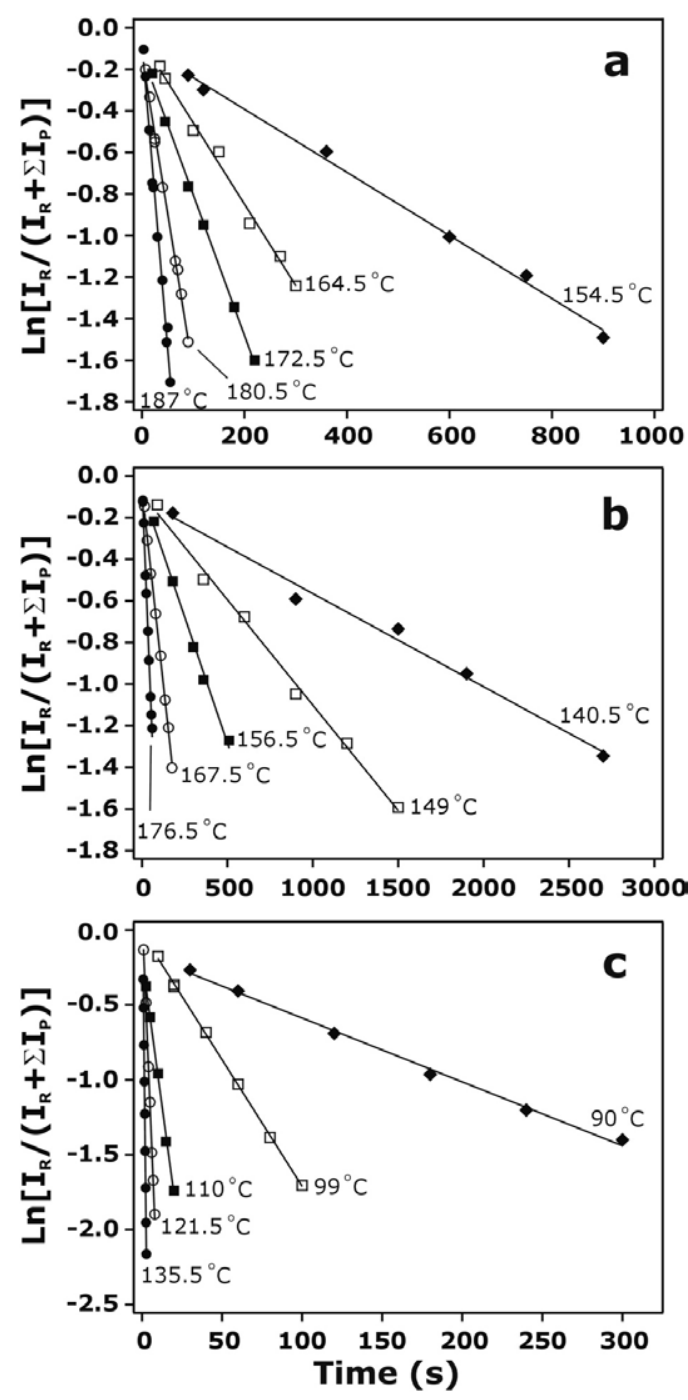

Figure 3. Dissociation kinetic data of (a) $\left(\mathrm{CT}_{14}\right)^{-3}$, (b) $\left(\mathrm{CT}_{19}\right)^{-3}$, and $(\mathrm{c})\left(\mathrm{AT}_{19}\right)^{-3}$ obtained at the temperatures indicated. 


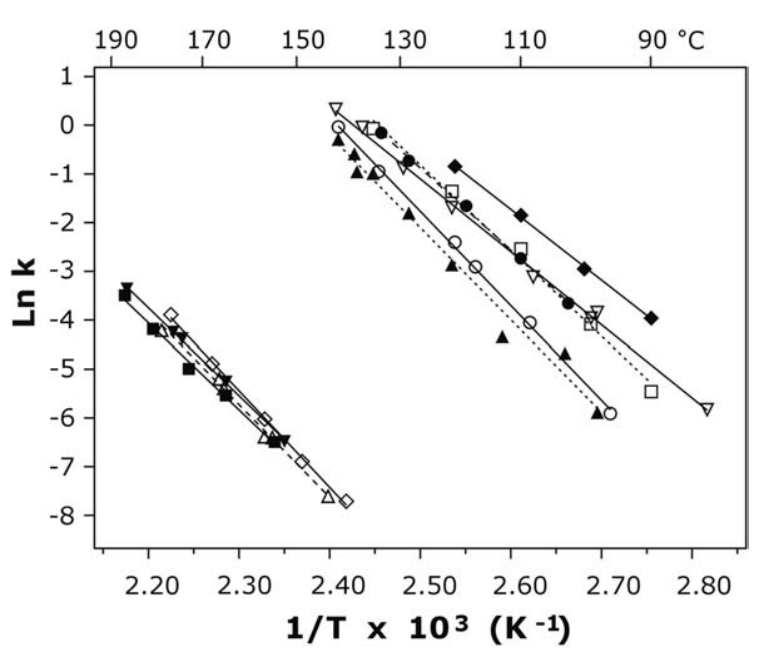

Figure 4. Arrhenius plots for the loss of neutral nucleobase from $\left(\mathrm{AT}_{14}\right)^{-2}$, (open inverted triangle); $\left(\mathrm{AT}_{14}\right)^{-3}$, (filled diamond); $\left(\mathrm{AT}_{19}\right)^{-2}$, (filled triangle); $\left(\mathrm{AT}_{19}\right)^{-3}$, (open square); $\left(\mathrm{T}_{19} \mathrm{~A}\right)^{-2}$, (open circle); $\left(\mathrm{T}_{19} \mathrm{~A}\right)^{-3}$, (filled circle); $\left(\mathrm{CT}_{14}\right)^{-2}$, (filled inverted triangle); $\left(\mathrm{CT}_{14}\right)^{-3}$, (filled square); $\left(\mathrm{CT}_{19}\right)^{-3}$, (open diamond); $\left(\mathrm{T}_{19} \mathrm{C}\right)^{-3}$, (open triangle).

$$
I_{R, \text { norm }}=I_{R} /\left(I_{R}+\Sigma I p\right)
$$

Arrhenius plots constructed from the temperaturedependent rate constants for the loss of nucleobase are shown in Figure 4. Reasonably linear Arrhenius plots were obtained for all of the ODN anions. The Arrhenius $E_{a}$ and $A$-factor were obtained from the slopes and $y$-intercepts, respectively, of a linear least-squares fit of the temperature-dependent kinetic data and the values are listed in Table 1. Arrhenius parameters previously determined for T-rich 10-mer anions with a single reactive base are included for comparison purposes. Also included in Table 1 are values for the entropy of activation $\left(\Delta S^{\ddagger}\right)$, calculated at a temperature of $150{ }^{\circ} \mathrm{C}$ from the corresponding $A$-factor using eq 4 .

$$
A=(\mathrm{ekT} / \mathrm{h}) \exp \left(\Delta S^{\ddagger} / R\right)
$$

Inspection of Figure 4 reveals that, over the temperature range investigated, the $\mathrm{C}$ - containing compounds exhibit very similar dissociation kinetics while the A-containing ions exhibit a much broader range of reactivity. It can also be seen that loss of $\mathrm{AH}$ from the 15- and 20-mers is significantly faster that the loss of $\mathrm{CH} ; \geq 3000$ times faster at $144{ }^{\circ} \mathrm{C}$. The enhanced reactivity of the A-containing ions, compared with C-containing ions, is even more striking given the similarity in $E_{a}$ values for their 20-mers, Table 1. It is also worth noting that the 15and 20-mers all react faster than their corresponding 10-mers, i.e., the $\mathrm{XT}_{9}^{-2}$ and $\mathrm{T}_{9} \mathrm{X}^{-2}$ ions [17]. The enhancement in reactivity is most pronounced for the A-containing ions, despite the larger $E_{a}$ values for their 15- and 20-mers, compared with the 10-mers.

Inspection of the Arrhenius parameters in Table 1 reveals a striking difference in the dependence of the A and $C$ base loss reactions on the size and charge state of the ODN anions. For the A-containing ions, the $E_{a}$ values are very sensitive to the size of the ODN. For example, for the $\mathrm{AT}_{\mathrm{m}}^{-2}$ series, the $E_{a}$ values increase from $25.9(\mathrm{~m}=9)$ to $29.7(\mathrm{~m}=14)$ to $37.8 \mathrm{kcal} \mathrm{mol}^{-1}(\mathrm{~m}$ $=19)$. A similar increase in $E_{a}$ is found for $\mathrm{T}_{\mathrm{m}} \mathrm{A}^{-2}$ ions, from $23.0(\mathrm{~m}=9)$ to $38.5 \mathrm{kcal} \mathrm{mol}^{-1}(\mathrm{~m}=19)$. An increase in charge state from, $n=2$ to 3 , for the $\mathrm{AT}_{19}^{-n}$ and $\mathrm{T}_{19} \mathrm{~A}^{-\mathrm{n}}$ ions results in a $5 \mathrm{kcal} \mathrm{mol}^{-1}$ decrease in $E_{a}$ values. However, no such charge effect is found for the $\mathrm{AT}_{14}^{-\mathrm{n}}$ anions, which exhibit similar $E_{a}$ values. In contrast to the results obtained for the A-containing ODN anions, the $E_{a}$ values for the C-containing ODN are relatively insensitive to size and charge state, with the exception of the $\mathrm{CT}_{19}^{-3}$ ion, which has an $E_{a}$ value of 39 $\mathrm{kcal} \mathrm{mol}^{-1}$, the $E_{a}$ values for the C-containing ODN fall within a $2 \mathrm{kcal} \mathrm{mol}^{-1}$ range, 35 to $37 \mathrm{kcal} \mathrm{mol}^{-1}$. Interestingly, the position ( $5^{\prime}$ or $\left.3^{\prime}\right)$ of $\mathrm{A}$ or $\mathrm{C}$ has only a small effect on the $E_{a}$ values. This is an intriguing result

Table 1. Arrhenius activation parameters for the loss of neutral nucleobase from some doubly and triply deprotonated oligodeoxynucleotide anions containing a single reactive base

\begin{tabular}{lccc}
\hline Oligodeoxynucleotide & $E_{a}\left(\mathrm{kcal} \mathrm{mol}^{-1}\right)^{\mathrm{a}}$ & $A\left(\mathrm{~s}^{-1}\right)^{\mathrm{a}}$ & $\Delta S^{\ddagger}\left(\mathrm{cal} \mathrm{mol}^{-1} \mathrm{~K}^{-1}\right)^{\mathrm{b}}$ \\
\hline \hline$\left(\mathrm{AT}_{9}-2 \mathrm{H}\right)^{-2}$ & $25.9 \pm 0.2^{\mathrm{c}}$ & $10^{12.1 \pm 0.1 \mathrm{c}}$ & -6 \\
$\left(\mathrm{AT}_{14}-2 \mathrm{H}\right)^{-2}$ & $29.7 \pm 0.6$ & $10^{15.8 \pm 0.3}$ & 11 \\
$\left(\mathrm{AT}_{14}-3 \mathrm{H}\right)^{-3}$ & $28.8 \pm 0.5$ & $10^{15.6 \pm 0.3}$ & 10 \\
$\left(\mathrm{AT}_{19}-2 \mathrm{H}\right)^{-2}$ & $37.8 \pm 1.9$ & $10^{19.8 \pm 1.0}$ & 29 \\
$\left(\mathrm{AT}_{19}-3 \mathrm{H}\right)^{-3}$ & $34.9 \pm 1.6$ & $10^{18.7 \pm 0.9}$ & 24 \\
$\left(\mathrm{~T}_{9} \mathrm{~A}-2 \mathrm{H}\right)^{-2}$ & $23.0 \pm 0.6^{\mathrm{c}}$ & $10^{10.5 \pm 0.3 \mathrm{c}}$ & -13 \\
$\left(\mathrm{~T}_{19} \mathrm{~A}-2 \mathrm{H}\right)^{-2}$ & $38.5 \pm 0.6$ & $10^{20.2 \pm 0.4}$ & 31 \\
$\left(\mathrm{~T}_{19} \mathrm{~A}-3 \mathrm{H}\right)^{-3}$ & $33.4 \pm 0.7$ & $10^{17.9 \pm 0.4}$ & 21 \\
$\left(\mathrm{CT}_{9}-2 \mathrm{H}\right)^{-2}$ & $34.6 \pm 1.1^{\mathrm{c}}$ & $10^{14.1 \pm 0.6 \mathrm{c}}$ & 3 \\
$\left(\mathrm{CT}_{14}-2 \mathrm{H}\right)^{-2}$ & $35.7 \pm 0.6$ & $10^{15.5 \pm 0.3}$ & 10 \\
$\left(\mathrm{CT}_{14}-3 \mathrm{H}\right)^{-3}$ & $35.3 \pm 1.7$ & $10^{15.2 \pm 0.8}$ & 8 \\
$\left(\mathrm{CT}_{19}-3 \mathrm{H}\right)^{-3}$ & $39.4 \pm 1.0$ & $10^{17.4 \pm 0.5}$ & 18 \\
$\left(\mathrm{~T}_{9} \mathrm{C}-2 \mathrm{H}\right)^{-2}$ & $37.2 \pm 2.3^{\mathrm{c}}$ & $10^{14.6 \pm 1.1 \mathrm{c}}$ & 6 \\
$\left(\mathrm{~T}_{19} \mathrm{C}-3 \mathrm{H}\right)^{-3}$ & $37.8 \pm 1.3$ & $10^{16.5 \pm 0.7}$ & 14 \\
\hline
\end{tabular}


given that it has been reported that fragmentation of ODN anions on the $3^{\prime}$ side of a $\mathrm{T}$ is generally enhanced compared with the $5^{\prime}$ side [1].

For the A-containing ODN ions, the $A$-factors fall in a broad range of values, $10^{10}-10^{20} \mathrm{~s}^{-1}$, which correspond to $\Delta S^{\ddagger}$ values of -13 to $31 \mathrm{cal} \mathrm{mol}^{-1} \mathrm{~K}^{-1}$. For the C-containing ions, the $A$-factors and $\Delta S^{\ddagger}$ values span a smaller range, $10^{14}-10^{17} \mathrm{~s}^{-1}$ and $6-18 \mathrm{cal} \mathrm{mol}^{-1} \mathrm{~K}^{-1}$, respectively. To put these values into perspective, it is useful to compare them with values reported for covalent bond cleavage reactions. For simple homolytic bond fission in small molecules, $A$-factors of $10^{14}$ to $10^{17}$ $\mathrm{s}^{-1}$ are typical, while values of $<10^{13} \mathrm{~s}^{-1}$ are generally associated with complex bond cleavage reactions involving cyclic transition states [20]. The $A$-factors for the loss of $\mathrm{CH}$ are similar to values expected for simple bond fission, which is consistent with cleavage of the $\mathrm{N}$-glycosidic bond as the rate-limiting step for neutral base loss. For the A-containing 10-mers, the relatively small $A$-factors suggest that the r-limiting step for the base loss reaction involves simultaneous bond cleavage and bond formation (i.e., a relatively tight transitionstate), while for the 15 -mers, the $A$-factors are more consistent with simple bond fission. The large $A$-factors determined for the 20-mers cannot be explained simply in terms of covalent bond cleavage. Large $A$-factors, $>10^{18} \mathrm{~s}^{-1}$, have previously only been reported for the dissociation of noncovalent biological complexes such as protein-carbohydrate and multiprotein complexes $[18,21,22]$. It has been suggested that these large $A$-factors arise from the softening of numerous vibrational modes upon cleavage of the stabilizing noncovalent intermolecular interactions [21]. The large $A$-factors determined for the 20-mers suggest, therefore, that the loss of $\mathrm{AH}$ is accompanied by the cleavage of multiple noncovalent interactions, likely involving solvation of the nucleobase. As described below, there is also evidence that internal solvation of the reactive nucleobase influences the Arrhenius parameters for the smaller A-containing ODN anions.

It is interesting to note that, for both the A- and C-containing ODN ions, the $E_{a}$ and $A$ values are highly correlated. However, the relationship between the $E_{a}$ and $A$ values is different for the two sets of ODN ions. For the A-containing ions, the average $E_{a} / \log A$ ratio is $1.9 \pm 0.1$, while for the $C$ ions, the average ratio is $2.3 \pm$ 0.1 . The difference in $E_{a} / \log A$ ratios determined for the loss of $\mathrm{AH}$ and $\mathrm{CH}$ indicates that, for a given $E_{a}$, the base loss reaction is inherently more favorable entropically for AH. Notably, the ratios determined for the A-containing ions are similar to those found for the dissociation of noncovalent protein-carbohydrate and multiprotein complexes in the gas phase. From an analysis of the Arrhenius parameters reported for the dissociation of protein complexes, the average $E_{a} / \log A$ value is found to be $2.0 \pm 0.1$ [23]. The origin of the correlation of $E_{a}$ and $A$ values for the protein complexes remains a matter of debate [18, 24]. Although artifacts arising from the statistical treatment of the kinetic data may obscure the true nature of the correlation, such energy-entropy correlation is thought to be an inherent characteristic of complexes stabilized by multiple, weak interactions (e.g., hydrogen bonds) [25]. The similarity in $E_{a} / \log A$ ratios for the A-containing ODN anions and the protein complexes further suggests that loss of $\mathrm{AH}$ requires the cleavage of noncovalent interactions. In contrast, the larger $E_{a} / \log A$ ratios found for the Ccontaining ions are more consistent with a reaction involving simple covalent bond cleavage (i.e., cleavage of the glycosidic linkage), than with noncovalent bond cleavage. That is not to say that $C$ is not internally solvated, rather that covalent bond cleavage represents the dominant energetic and entropic contributions to the Arrhenius parameters.

The differential internal solvation of $A$ and $C$ within the T-rich ODN anions provides a reasonable explanation for the observed dependence of the $E_{a}$ and $A$ values with ODN size and charge state. As the A-containing ions get bigger and, presumably, conformationally more flexible, the intramolecular solvation of A might be expected to be enhanced and lead to larger Arrhenius parameters. Furthermore, the smaller $E_{a}$ and $A$ values for the triply charged $\mathrm{AT}_{19}$ and $\mathrm{T}_{19} \mathrm{~A}$ ions, compared with the doubly charged ions, is consistent with reduced base solvation with increasing charge state due to Coulombic repulsion, which is expected to cause the ions to adopt more extended conformations [26]. In contrast, the limited sensitivity of the Arrhenius parameters for the loss of $\mathrm{CH}$ to size and charge state of the ODN is consistent with a simple covalent bond cleavage reaction (i.e., heterolytic cleavage of the glycosidic linkage) with little or no contribution from intramolecular interactions.

The above interpretation of the Arrhenius parameters, if correct, may provide new insight into the relative strength of the $\mathrm{N}$-glycosidic linkages for $\mathrm{A}$ and $\mathrm{C}$. If the Arrhenius parameters for the loss of $\mathrm{AH}$ correspond predominantly to the cleavage of noncovalent interactions stabilizing the nucleobase and the extent of base solvation decreases with decreasing length of the ODN, then for sufficiently small strands, the dissociation $E_{a}$ value should reflect the $\mathrm{N}$-glycosidic bond cleavage process, with little or no contribution from solvation effects. In the absence of parameters for A-containing ODN anions shorter than 10-mers, the values obtained for the 10-mers in the previous BIRD study, $\sim 23 \mathrm{kcal}$ $\mathrm{mol}^{-1}$, may be taken as the upper limit for the $E_{a}$ for glycosidic bond cleavage for A. In contrast, the $E_{a}$ values determined for the loss of $\mathrm{CH}, \sim 35 \mathrm{kcal} \mathrm{mol}^{-1}$, do not appear to be significantly influenced by internal solvation of nucleobase and may reflect the energy required to cleave the glycosidic bond.

While the above analysis of the Arrhenius parameters does not provide any direct insight into the mechanism of base loss from gaseous ODN anions, it is interesting to note the similarities between the relative reactivity and $E_{a}$ values of $A$ and $C$ in the gas phase and in solution. It is well established that depurination (loss 
of $\mathrm{AH}$ or $\mathrm{GH}$ ) of DNA is kinetically more facile that depyrimidination (loss of $\mathrm{TH}$ or $\mathrm{CH}$ ) in aqueous solution [27]. The differential reactivity of $A$ and $C$ reflects, at least in part, a difference in the $E_{a}$ for glycosidic bond cleavage, $31 \mathrm{kcal} \mathrm{mol}^{-1}$ for A [28] and $35 \mathrm{kcal} \mathrm{mol}^{-1}$ for $C$ [29]. In solution, the base loss reaction is believed to be acid catalyzed, with protonation of the nucleobase resulting in a weakening of the glycosidic bond. Interestingly, an analogous acid catalysis mechanism has been proposed for the base loss reactions in the gas phase by Gross and coworkers [16]. According to this mechanism, the nucleobase is charged by proton transfer from an adjacent phosphate group before cleavage of the glycosidic bond. The similarities between the relative reactivity and $E_{a}$ values in solution and gas phase are consistent with this acid catalyzed base loss mechanism.

\section{Hydrogen/Deuterium Exchange}

Gas-phase H/D exchange is a promising technique for identifying differences in the higher order structure of biopolymers [30-32]. For example, differences in H/D exchange rates have been measured for protein ions generated by ES from native and denaturing conditions [30]. H/D exchange has also been used to monitor time-dependent structural changes in ODN anions in the gas phase $[33,34]$. Studies of H/D exchange in mono- and oligonucleotides anions have suggested that exchange involves inter- and intramolecular proton transfer involving the phosphate groups [34]. It has also been shown that the presence of internal hydrogen bonds within the ODN anions slows down the rate of exchange $[33,34]$. Therefore, differences in base solvation in the T-rich ODN ions investigated in the present study may lead to differences in the rate of $\mathrm{H} / \mathrm{D}$ exchange. In addition to possible base stacking, the intramolecular solvation of the nucleobases within the ODN anions is expected to involve neutral and ionic hydrogen bonds with other nucleobases, phosphate groups and deoxyribose $\mathrm{OH}$ groups [34, 35]. As such, the differential solvation of $\mathrm{A}$ and $\mathrm{C}$ in the larger T-rich ODN anions (in particular the 20-mers) predicted by the BIRD experiments might be revealed by gas-phase H/D exchange experiments.

To investigate whether conformational differences among the A- and C-containing 20-mers could be identified using gas-phase $\mathrm{H} / \mathrm{D}$ exchange, experiments were carried out on the triply deprotonated $\mathrm{AT}_{19}^{-3}$, $\mathrm{T}_{19} \mathrm{~A}^{-3}, \mathrm{CT}_{19}^{-3}$, and $\mathrm{T}_{19} \mathrm{C}^{-3}$ anions using $\mathrm{D}_{2} \mathrm{O}$ as the deuterating agent. Each triply deprotonated ion possesses 39 possible exchangeable hydrogens, belonging to the imino, amino, hydroxyl and phosphate groups. After isolating their naturally occurring isotopes, each of the four ions were allowed to react with $\mathrm{D}_{2} \mathrm{O}$ for 300 , 600, and 900 s. Shown in Figure 5 are mass spectra obtained for each of the four ions at each time interval. Reported in Table 2 is the change in average mass of the ODN anions due to the incorporation of deuterons in
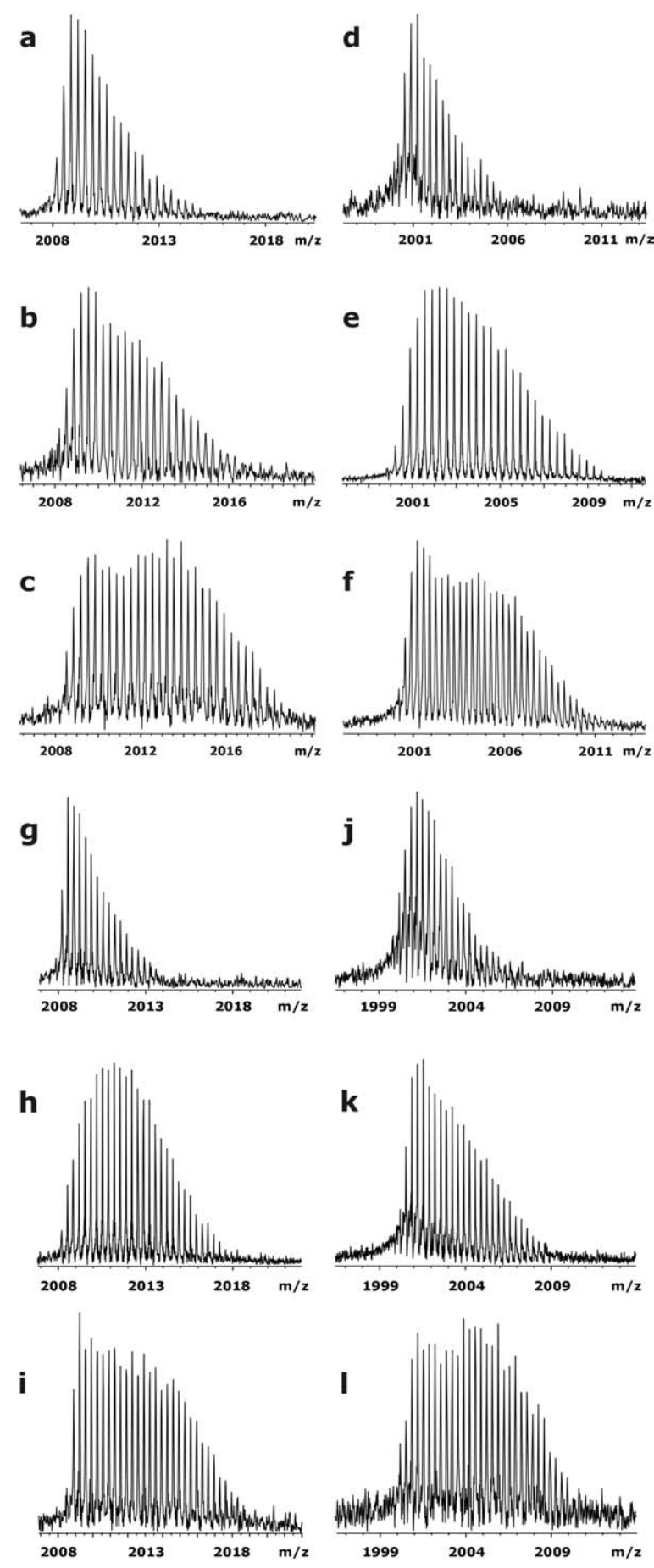

Figure 5. H/D exchange mass spectra of $\left(\mathrm{AT}_{19}\right)^{-3}$ at (a) $300 \mathrm{~s},(\mathbf{b})$ $600 \mathrm{~s},(\mathrm{c}) 900 \mathrm{~s},\left(\mathrm{CT}_{19}\right)^{-3}$ at (d) $300 \mathrm{~s},(\mathrm{e}) 600 \mathrm{~s},(\mathrm{f}) 900 \mathrm{~s},\left(\mathrm{~T}_{19} \mathrm{~A}\right)^{-3}$ at (g) $300 \mathrm{~s},(\mathrm{~h}) 600 \mathrm{~s}$, (i) 900, and $\left(\mathrm{T}_{19} \mathrm{C}\right)^{-3}$ at (j) $300 \mathrm{~s},(\mathbf{k}) 600 \mathrm{~s},(\mathbf{l})$ $900 \mathrm{~s}$.

each exchange-time interval. The weighted average mass, $\mathrm{m}_{\mathrm{ave}}$, at each time interval was calculated using eq 5

$$
\mathrm{m}_{\text {ave }}=\sum \mathrm{f}_{\mathrm{i}} \mathrm{m}_{\mathrm{i}}
$$

where $m_{i}$ and $f_{i}$ are the mass and fractional abundance, respectively, of the ODN isotopes. The change in average mass, $\Delta \mathrm{m}$, is given by eq 6 
Table 2. Average number of exchanged hydrogens $(\Delta \mathrm{m})$ as a function of exchange time ${ }^{\text {ab }}$

\begin{tabular}{lccc}
\hline ODN anion & $300 \mathrm{~s}$ & $600 \mathrm{~s}$ & $900 \mathrm{~s}$ \\
\hline \hline$\left(\mathrm{AT}_{19}\right)^{-3}$ & 4.7 & 7.7 & 10.1 \\
$\left(\mathrm{CT}_{19}\right)^{-3}$ & 4.1 & 9.0 & 11.2 \\
$\left(\mathrm{~T}_{19} \mathrm{~A}\right)^{-3}$ & 3.5 & 9.8 & 11.7 \\
$\left(\mathrm{~T}_{19} \mathrm{C}\right)^{-3}$ & 5.2 & 8.4 & 12.2 \\
\hline
\end{tabular}

${ }^{\mathrm{a}}$ Calculated from eq 5 and 6 .

${ }^{b} \mathrm{D}_{2} \mathrm{O}$ was used as exchange reagent at a static pressure of $7.0 \times 10^{-10}$ mbar (uncorrected).

$$
\Delta \mathrm{m}(t)=\mathrm{m}_{\text {ave }}(t)-\mathrm{m}_{\text {ave }}(0)
$$

where $m_{a v e}(0)$ is the average mass at time zero, i.e., the average mass of the naturally occurring isotopes of the ODN, and $\mathrm{m}_{\text {ave }}(t)$ is the average mass measured at time $t$.

Inspection of the $\Delta \mathrm{m}$ values reported in Table 2 reveals that there are differences in average exchange rates determined for the four ODN ions: at $300 \mathrm{~s}$, the $\Delta \mathrm{m}$ values range from $3.5\left(\mathrm{~T}_{19} \mathrm{~A}^{-3}\right)$ to $5.2\left(\mathrm{~T}_{19} \mathrm{C}^{-3}\right)$, at $600 \mathrm{~s}$ the values range from $7.7\left(\mathrm{AT}_{19}^{-3}\right)$ to $9.8\left(\mathrm{~T}_{19} \mathrm{~A}^{-3}\right)$ while at $900 \mathrm{~s}$ the values range from $10.1\left(\mathrm{AT}_{19}^{-3}\right)$ to $12.2\left(\mathrm{~T}_{19} \mathrm{C}^{-3}\right)$. However, the differences in the $\Delta \mathrm{m}$ values are too small to be considered significant within the uncertainty of the experimental measurements. Consequently, it is concluded that the H/D exchange experiments do not provide evidence of differences in the degree of internal solvation within the A- and C-containing ODN anions.

\section{BIRD of Noncovalent $\left(T_{20}+X H\right)^{-3}$ Complexes}

The BIRD experiments, if not the H/D exchange experiments, suggest that there are differences in the higher order structures of $\mathrm{A}$ - and C-containing T-rich ODN anions. These structural differences are attributed, at least in part, to inherent differences in the internal solvation of the covalently bound $\mathrm{A}$ and $\mathrm{C}$ bases within the anions. It was also of interest to establish whether the $\mathrm{A}$ and $\mathrm{C}$ bases, when bound noncovalently to T-rich ODN anions, exhibit differences in intermolecular solvation. To address this question, BIRD was performed on the complexes of triply deprotonated $\mathrm{T}_{20}$ and $\mathrm{AH}$ or $\mathrm{CH}$, i.e., $\left(\mathrm{T}_{20}+\mathrm{XH}\right)^{-3}$. The noncovalent complexes were produced by performing nanoES on solutions containing $\mathrm{T}_{20}$ and the nucleobase $\mathrm{AH}$ or $\mathrm{CH}$ at relatively high concentration $(\sim 50 \mu \mathrm{M})$. Dissociation of the $\left(\mathrm{T}_{20}+\right.$ $\mathrm{XH})^{-3}$ complexes proceeds exclusively by the loss of the neutral base $(\mathrm{XH})$, eq 7 .

$$
\left(\mathrm{T}_{20}+\mathrm{XH}\right)^{-3} \rightarrow \mathrm{T}_{20}^{-3}+\mathrm{XH}
$$

Shown in Figure 6 are kinetic plots obtained at several temperatures for the dissociation of the $\left(\mathrm{T}_{20}+\mathrm{AH}\right)^{-3}$ and $\left(\mathrm{T}_{20}+\mathrm{CH}\right)^{-3}$ ions. The plots are linear and, except at the lowest temperatures investigated, exhibit near zero intercepts. Shown in Figure 7 are the Arrhenius plots constructed from the temperature-dependent dissociation rate constants.
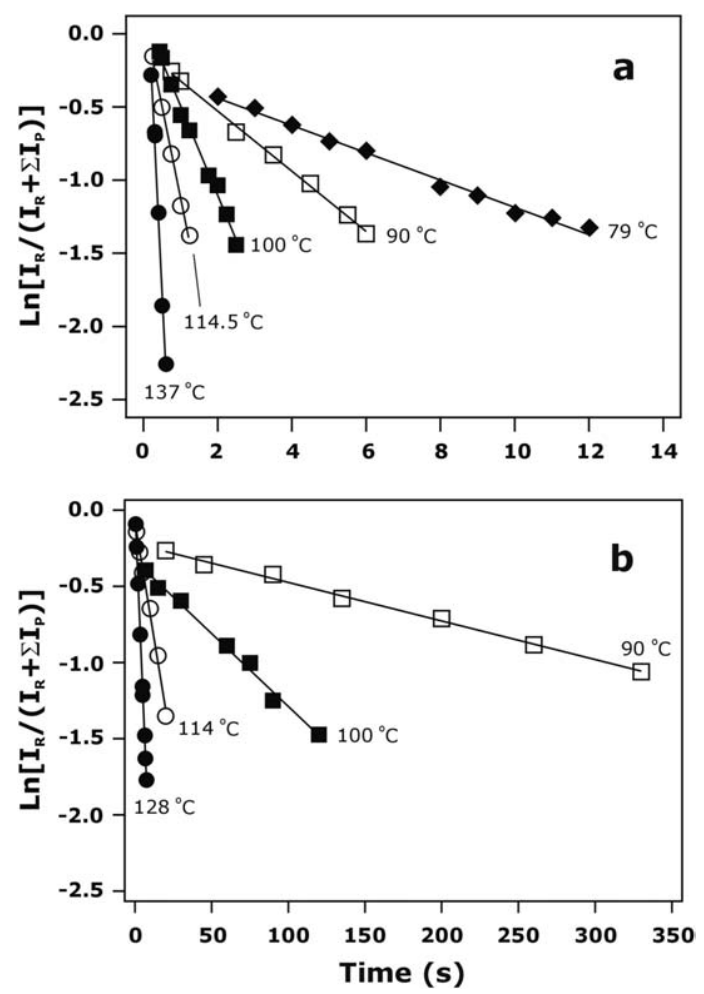

Figure 6. Kinetic data, obtained at the temperatures indicated, for the dissociation of the $\left(\mathrm{T}_{20}+\mathrm{XH}\right)^{-3}$ complexes into $\mathrm{T}_{20}^{-3}$ and $\mathrm{XH}$; (a) $\left(\mathrm{T}_{20}+\mathrm{AH}\right)^{-3}$ and (b) $\left(\mathrm{T}_{20}+\mathrm{CH}\right)^{-3}$.

It can be seen that the kinetic and energetic stabilities of the $\left(\mathrm{T}_{20}+\mathrm{AH}\right)^{-3}$ and $\left(\mathrm{T}_{20}+\mathrm{CH}\right)^{-3}$ ions are very different. Over the range of temperatures investigated, $\left(\mathrm{T}_{20}+\mathrm{AH}\right)^{-3}$ is at least seven times more reactive than $\left(\mathrm{T}_{20}+\mathrm{CH}\right)^{-3}$. The lower kinetic stability of $\left(\mathrm{T}_{20}+\right.$ $\mathrm{AH})^{-3}$ coincides with significantly smaller $E_{a}$ and $A$ values, $19.8 \pm 1.0 \mathrm{kcal} \mathrm{mol}^{-1}$ and $10^{11.3} \pm 0.6 \mathrm{~s}^{-1}$, compared with $\left(\mathrm{T}_{20}+\mathrm{CH}\right)^{-3}, 34.9 \pm 1.3 \mathrm{kcal} \mathrm{mol}^{-1}$, and $10^{18.4} \pm 0.7 \mathrm{~s}^{-1}$. Taken on their own, the Arrhenius parameters suggest that there are significant differences in how the two bases interact with $\mathrm{T}_{20}^{-3}$. While these

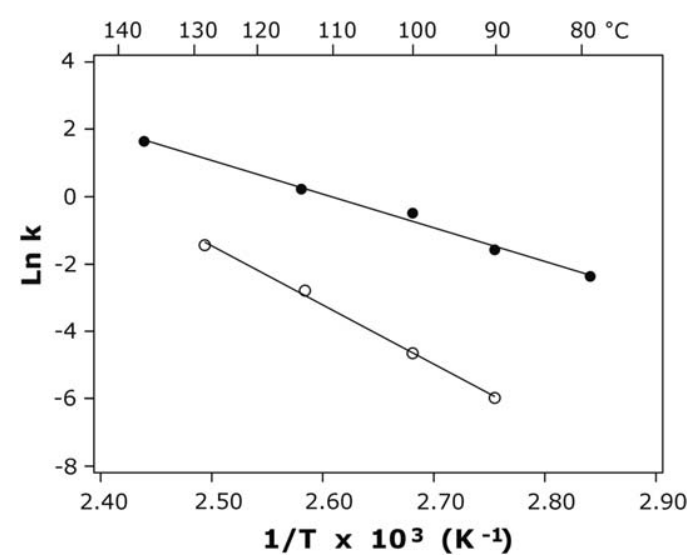

Figure 7. Arrhenius plots for the dissociation of the $\left(\mathrm{T}_{20}+\mathrm{XH}\right)^{-3}$ complexes into $\mathrm{T}_{20}^{-3}$ and $\mathrm{XH} ;\left(\mathrm{T}_{20}+\mathrm{AH}\right)^{-3}$, (filled circle) and $\left(\mathrm{T}_{20}\right.$ $+\mathrm{CH})^{-3}$, (open circle). 
structural differences can not be positively identified from the dissociation data, it is possible to speculate on the nature of the interactions. Primary sites of interaction of the free base with the $\mathrm{T}_{20}^{-3}$ ion may include one of the deprotonated phosphate groups or one (or more) of the neutral thymine bases. Given that the nucleobases are relatively acidic in the gas phase $\left(\Delta \mathrm{H}_{\text {acid }}(\mathrm{AH})=327\right.$

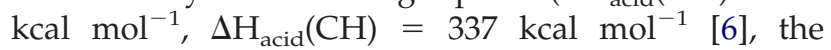
energetically preferred site of interaction might be one of the charged phosphate groups $\left(\Delta \mathrm{H}_{\text {acid }}\left[\mathrm{CH}_{3}\right]_{2} \mathrm{PO}_{4} \mathrm{H}\right)$ $=321 \mathrm{kcal} \mathrm{mol}^{-1}$ [36]. Because the difference in acidity between the phosphate group and $\mathrm{AH}$ is less than the difference for $\mathrm{CH}, \mathrm{AH}$ would be expected to form the strongest ionic hydrogen bond. However, this is not consistent with the experimental results. One possible explanation for this is that $\mathrm{CH}$ participates in additional hydrogen bonds with the same phosphate group or with adjacent phosphate groups. To our knowledge, Arrhenius parameters for the dissociation of noncovalent complexes of deprotonated phosphate groups and small neutral molecules have not been reported. Williams and coworkers have estimated the dissociation threshold energy for the $\mathrm{H}_{3} \mathrm{PO}_{4} \cdot \mathrm{H}_{2} \mathrm{PO}_{4}^{-}$complex to be $\sim 30 \mathrm{kcal} \mathrm{mol}^{-1}$ [37]. However, it is difficult to compare this value directly with the present $E_{a}$ values because $\mathrm{H}_{3} \mathrm{PO}_{4}$ is more acidic than $\mathrm{AH}$ or $\mathrm{CH}$ and can, in principle, form a stronger ionic hydrogen bond than either of the nucleobases. Furthermore, the $\mathrm{H}_{3} \mathrm{PO}_{4} \cdot \mathrm{H}_{2} \mathrm{PO}_{4}^{-}$complex is likely stabilized by multiple intermolecular hydrogen bonds, which may not be the case for $\mathrm{AH}$ or $\mathrm{CH}$. A second possible site of interaction of the free bases is one of the neutral $\mathrm{T}$ bases. According to theoretical calculations of the hydrogen bond energy for DNA base pairs in the gas phase, the interaction of $\mathrm{TH}$ with $\mathrm{AH}$ is energetically more favorable, by several $\mathrm{kcal} \mathrm{mol}^{-1}$, than is the interaction with $\mathrm{CH}$. This is true even when considering only the hydrogen bonds that are possible within the $\left(\mathrm{T}_{20}+\mathrm{XH}\right)^{-3}$ complexes. According to the most recent DFT calculations, the A-T interaction energy may be as large as $17 \mathrm{kcal} \mathrm{mol}^{-1}$ [38]. Based on the similarity between the theoretical A-T interaction energy value and the experimental dissociation $E_{a}$ for the $\left(\mathrm{T}_{20}+\mathrm{AH}\right)^{-3}$ complex, $\sim 20 \mathrm{kcal} \mathrm{mol}^{-1}$, the possibility of neutral A-T interactions in the $\left(\mathrm{T}_{20}\right.$ $+\mathrm{AH})^{-3}$ complex cannot be ruled out. However, for the $\left(\mathrm{T}_{20}+\mathrm{CH}\right)^{-3}$ complex, the large $E_{a}$ is inconsistent with simple $\mathrm{C}-\mathrm{T}$ interaction. More likely, $\mathrm{CH}$ interacts at a charged phosphate group with, perhaps, additional hydrogen bonding interactions contributing to the stability of the complex.

The present results suggest different interaction sites for $\mathrm{AH}$ and $\mathrm{CH}$ within the $\left(\mathrm{T}_{20}+\mathrm{XH}\right)^{-3}$ complexes. Given that solvation of a deprotonated phosphate group would be expected to be, energetically, the most favorable intermolecular interaction for both $\mathrm{AH}$ and $\mathrm{CH}$, this result is intriguing. A possible explanation for the alternative binding site in the case of the $\left(\mathrm{T}_{20}+\right.$ $\mathrm{AH})^{-3}$ complex would be that the base-base (A-T) interactions were present in solution and were nominally preserved upon transfer to the gas phase. In other words, the $\mathrm{A}$ and $\mathrm{T}$ bases engage in specific $\mathrm{H}$-bonding in solution and the interactions become "kinetically" trapped in the gas phase. Some support for this explanation can be found in a study reported by Gokel and coworkers [39]. Using ES/MS, the interactions between diaza-18-crown 6 derivatives with two sidearms terminating in either adenine (referred to as $\mathrm{AOA}$ ) or thymine (TOT) in a solution of $\mathrm{CH}_{3} \mathrm{Cl} / \mathrm{CH}_{3} \mathrm{OH}$ were investigated. The authors observed the preferential formation of the protonated complex TOT-AOA, a result that suggests specific base-base interactions in solution. In contrast, the $\left(\mathrm{T}_{20}+\mathrm{CH}\right)^{-3}$ complex is likely produced from nonspecific interactions during the nanoES process. With no preorganization of the structure of the complex, the base is likely able to migrate to the preferred site of interaction, i.e., the deprotonated phosphate group, in the gas phase.

\section{Conclusions}

The present work details the application of the BIRD technique to study thermal decomposition of a series of T-rich doubly and triply deprotonated 15- and 20-mer ODN anions containing a single reactive nucleobase (A or $\mathrm{C}$ ). From the temperature dependence of the dissociation kinetics, Arrhenius activation parameters for the loss of neutral nucleobase from the ODN anions have been determined. In agreement with an earlier study of doubly deprotonated 10-mer ODN anions, the A-containing ODN anions are significantly more reactive ( $\geq 3000$ times at $144{ }^{\circ} \mathrm{C}$ ) than the C-containing ions. Interestingly, the Arrhenius activation parameters for the loss of base from the $\mathrm{C}$-containing ions are relatively insensitive to the size and charge state of the ODN. In contrast, the parameters for the loss of base from the A-containing ions exhibit a strong dependence on size and, to some extent, charge state, with the parameters increasing with size and charge state. The $A$-factors for the loss of $\mathrm{CH}$, which are in the range of $10^{15}$ to $10^{17} \mathrm{~s}^{-1}$, are consistent with simple bond cleavage as the ratelimiting step. The $A$-factors for the loss of $\mathrm{AH}$ increase with increasing size, $10^{11}-10^{12} \mathrm{~s}^{-1}$ (10-mers), $10^{15}-10^{16}$ $\mathrm{s}^{-1}$ (15-mers), and $10^{18}-10^{20} \mathrm{~s}^{-1}$ (20-mers). These results are consistent with greater internal solvation of $\mathrm{A}$ with increasing size of the ODN anions.

Gas-phase H/D exchange experiments were performed on $\mathrm{AT}_{19}^{-3}, \mathrm{~T}_{19} \mathrm{~A}^{-3}, \mathrm{CT}_{19}^{-3}$, and $\mathrm{T}_{19} \mathrm{C}^{-3}$ anions, using $\mathrm{D}_{2} \mathrm{O}$ as the deuterating agent, in an effort to identify differences in intramolecular solvation of $\mathrm{A}$ and $\mathrm{C}$. However, the $\mathrm{H} / \mathrm{D}$ exchange results were inconclusive. BIRD was also performed on noncovalent complexes formed between $\mathrm{T}_{20}^{-3}$ and $\mathrm{AH}$ or $\mathrm{CH}$, i.e., $\left(\mathrm{T}_{20}+\right.$ $\mathrm{XH})^{-3}$. Dissociation of complexes was found to proceed exclusively by the loss of $\mathrm{XH}$. Interestingly, the nature of the noncovalently bound nucleobase had a significant influence on the magnitude of the Arrhenius parameters, $20 \mathrm{kcal} \mathrm{mol}^{-1}$ and $10^{11} \mathrm{~s}^{-1}$ for $\left(\mathrm{T}_{20}+\mathrm{AH}\right)^{-3}$ 
compared with $35 \mathrm{kcal} \mathrm{mol}^{-1}$ and $10^{18} \mathrm{~s}^{-1}$ for $\left(\mathrm{T}_{20}+\right.$ $\mathrm{CH})^{-3}$. The difference in the Arrhenius parameters indicates significant differences in the nature of the intermolecular interactions. It is speculated that in the $\left(\mathrm{T}_{20}+\mathrm{CH}\right)^{-3}$ complex, which is likely formed via nonspecific interactions during the nanoES process, the $\mathrm{CH}$ interacts at a charged phosphate group with, perhaps, additional hydrogen bonding interactions contributing to the stability of the complex. In contrast, specific A-T hydrogen bonding in solution may lead to a gaseous $\left(\mathrm{T}_{20}+\mathrm{AH}\right)^{-3}$ complex in which the $\mathrm{AH}$ interacts with $\mathrm{T}$ residues, instead of a charged phosphate group.

\section{Acknowledgments}

Financial support provided by the Natural Sciences and Engineering Research Council of Canada (NSERC). The authors thank E. N. Kitova and A. T. Blades for helpful comments during the preparation of the manuscript.

\section{References}

1. Hofstadler, S. A.; Sannes-Lowry, K. A.; Hannis, J. C. Analysis of Nucleic Acids by FTICR MS. Mass Spectrom. Rev. 2005, 24, 265-285.

2. McLuckey, S. A.; Van Berkel, G. J.; Glish, G. L. Tandem Mass spectrometry of Small, Multiply Charged Oligonucleotides. J. Am. Soc. Mass Spectrom. 1992, 3, 60-70.

3. Wan, K. X.; Gross, M. L. Fragmentation Mechanisms of Oligodeoxynucleotides: Effects of Replacing Phosphates with Methylphosphates and Thymines with Other Bases in T-Rich Sequences. J. Am. Soc. Mass Spectrom. 2001, 12, 580-589.

4. Wan, K. X.; Gross, J.; Hillenkamp, F.; Gross, M. L. Fragmentation Mechanisms of Oligodeoxynucleotides Studies by H/D Exchange and Electrospray Ionization Tandem Mass Spectrometry. J. Am. Soc. Mass Spectrom. 2001, 12, 193-205.

5. McLuckey, S. A.; Habibi-Goudarzi, S. Decompositions of Multiply Charged Oligonucleotide Anions. J. Am. Chem. Soc. 1993, 115, 1208512095 .

6. Freitas, M. A.; Shi, S. D.-H.; Hendrickson, C. L.; Marshall, A. G. Gas-phase RNA and DNA Ions. 1. H/D Exchange of the $[\mathrm{M}-\mathrm{H}]^{-}$ Anions of Nucleoside 5'-Monophosphates (GMP, dGMP, AMP, dAMP, CMP, dCMP, UMP, dTMP), Ribose 5-Monophosphate, and 2-Deoxyribose 5-Monophosphate with $\mathrm{D}_{2} \mathrm{O}$ and $\mathrm{D}_{2} \mathrm{~S}$. J. Am. Chem. Soc. 1998, 120, 10187-10193.

7. McLuckey, S. A.; Vaidyanathan, G. Charge State Effects in the Decompositions of Single-Nucleobase Oligonucleotide Polyanions. Int. J. Mass Spectrom. Ion Processes 1997, 162, 1-16.

8. Little, D. P.; Aaserud, D. J.; Valaskovic, G. A.; McLafferty, F. W. Sequence Information from 42-108-mer DNAs (Complete for a 50-mer) by Tandem Mass Spectrometry. J. Am. Chem. Soc. 1996, 118, 9352-9359.

9. Luo, H.; Lipton, M. S.; Smith, R. D. Charge Effects for Differentiation of Oligodeoxynucleotide Isomers Containing 8-oxo-dG Residues. J. Am. Soc. Mass Spectrom. 2002, 13, 195-199.

10. Hannis, J. C.; Muddiman, D. C. Tailoring the Gas-Phase Dissociation and Determining the Relative Energy of Activation for Dissociation of 7-deaza Purine Modified Oligonucleotides Containing a Repeating Motif. Int. I. Mass Spectrom. 2002, 219, 139-150.

11. Zhu, L.; Parr, G. R.; Fitzgerald, M. C.; Nelson, C. M.; Smith, L. M. Oligodeoxynucleotide Fragmentation in MALDI/TOF Mass Spectrometry Using 355-nm Radiation. J. Am. Chem. Soc. 1995, 117, 6048-6056.

12. McLuckey, S. A.; Vaidyanathan, G.; Habibi-Goudarzi, S. Charged vs. Neutral Nucleobase Loss from Multiply Charged Oligonucleotide Anions. J. Mass Spectrom. 1995, 30, 1222-1229.

13. Aaserud, D. J.; Guan, Z.; Little, D. P.; McLafferty, F. W. DNA Sequencing with Blackbody Infrared Radiative Dissociation of Electrosprayed Ions. Int. J. Mass Spectrom. Ion Processes 1997, 167/168, 705-7012.

14. Klassen, J. S.; Schnier, P. D.; Williams, E. R. Blackbody Infrared Radiative Dissociation of Oligonucleotide Anions. J. Am. Soc. Mass Spectrom. 1998, 9, 1117-1124.
15. Lotz, R.; Gerster, M.; Bayer, E. Sequence Verification of Oligodeoxynucleotides and Oligophosphorothioates Using Electrospray Ionization (Tandem) Mass Spectrometry. Rapid Commun. Mass Spectrom. 1998, 12, 389-397.

16. Wang, Z.; Wan, K. X.; Ramanathan, R.; Taylor, J. S.; Gross, M. L. Structure and Fragmentation Mechanisms of Isomeric T-Rich Oligodeoxynucleotides: A Comparison of Four Tandem Mass Spectrometric Methods. J. Am. Soc. Mass Spectrom. 1998, 9, 683-691.

17. Daneshfar, R.; Klassen, J. S. Arrhenius Activation Parameters for the Loss of Neutral Nucleobases from Deprotonated Oligonucleotide Anions in the Gas Phase. J. Am. Soc. Mass Spectrom. 2004, 15, 55-64.

18. Felitsyn, N.; Kitova, E. N.; Klassen, J. S. Thermal Decomposition of a Gaseous Multiprotein Complex Studied by Blackbody Infrared Radiative Dissociation. Investigating the Origin of the Asymmetric Dissociation Behavior. Anal. Chem. 2001, 73, 4647-4661.

19. Marshall, A. G.; Grosshans, P. B. Fourier-Transform Ion Cyclotron Resonance Mass spectrometry-the Teenage Years. Anal. Chem. 1991, 63, 215A-229A

20. Benson, S. W.; Thermochemical Kinetics. Methods for the Estimation of Thermochemical data and Rate Parameters; Wiley: New York, 1968; pp $78-140$.

21. Kitova, E. N.; Bundle, D. R.; Klassen, J. S. Thermal Dissociation of Protein-Oligosaccharide Complexes in the Gas Phase: Mapping the Intrinsic Intermolecular Interactions. J. Am. Chem. Soc. 2002, 124, 59025913.

22. Wang, W.; Kitova, E. N.; Klassen, J. S. Bioactive Recognition Sites May not be Energetically Preferred in Protein-Carbohydrate Complexes in the Gas Phase. J. Am. Chem. Soc. 2003, 125, 13630-13631.

23. Kitova, E. N.; Klassen, J. S. Intrinsic Energy-Entropy Compensation in Gaseous Biomolecular Complexes. Proceedings of the 53rd ASMS Conference on Mass Spectrometry and Allied Topics; San Antonio, TX, June, 2005.

24. Laskin, J.; Futrell, J. H. Entropy is the Major Driving Force for Fragmentation of Proteins and Protein-Ligand Complexes in the Gas Phase. J. Phys. Chem. A 2003, 107, 5836-5839.

25. Dunitz, J. D. Win Some, Lose Some: Enthalpy-Entropy Compensation in weak Intermolecular Interactions. Chem. Biol. 1995, 2, 709-712.

26. Hoaglund, C. S.; Liu, Y.; Ellington, A. D.; Pagel, M.; Clemmer, D. E. Gas-Phase DNA: Oligothymidine Ion Conformers. J. Am. Chem. Soc. 1997, 119, 9051-9052.

27. Lindahl, T.; Karlstrom, O. Heat-Induced Depyrimidination of Deoxyribonucleic Acid in Neutral Solution. Biochemistry 1973, 12, 5151-5154.

28. Lindahl, T.; Nyberg, B. Rate of Depurination of Native Deoxyribonucleic Acid. Biochemistry 1972, 11, 3610-3618.

29. Shapiro, R.; Danzig, M. Acidic Hydrolysis of Deoxycytidine and Deoxyuridine Derivatives. The General Mechanism of Deoxyribonucleoside Hydrolysis. Biochemistry 1972, 11, 23-29.

30. Winger, B. E.; Light-Wahl, K. J.; Rockwood, A. L.; Smith, R. D. Probing Qualitative Conformation Differences of Multiply Protonated GasPhase Proteins via H/D Isotopic Exchange with $\mathrm{D}_{2}$ O. J. Am. Chem. Soc. 1992, 114, 5897-5898

31. Suckau, D.; Shi, Y.; Beu, S. C.; Senko, M. W.; Quinn, J. P.; Wampler, F. M.; McLafferty, F. W. Coexisting Stable Conformations of Gaseous Protein Ions. Proc. Natl. Acad. Sci. U.S.A. 1993, 90, 790-793.

32. Campbell, S.; Rodgers, M. T.; Marzulff, E. M.; Beauchamp, J. L. Deuterium Exchange Reactions as a Probe of Biomolecule Structure. Fundamental Studies of Gas Phase H/D Exchange Reactions of Protonated Glycine Oligomers with $\mathrm{D}_{2} \mathrm{O}, \mathrm{CD}_{3} \mathrm{OD}, \mathrm{CD}_{3} \mathrm{CO}_{2} \mathrm{D}$, and $\mathrm{ND}_{3}$. J. Am. Chem. Soc. 1995, 117, 12840-12854.

33. Griffey, R. H.; Greig, M. J.; Robinson, J. M.; Laude, D. A. Gas-Phase Hydrogen-Deuterium Exchange in Phosphorothioate d(GTCAG) and d(TCGAT). Rapid Commun. Mass Spectrom. 1999, 13, 113-117.

34. Robinson, J. M.; Greig, M. J.; Griffey, R. H.; Mohan, V.; Laude, D. A. Hydrogen/Deuterium Exchange of Nucleotides in the Gas Phase. Anal. Chem. 1998, 70, 3566-3571.

35. Habibi-Goudarzi, S.; McLuckey, S. A. Ion Trap Collisional Activation of the Deprotonated Deoxymononucleoside and Deoxydinucleoside Monophosphates. J. Am. Soc. Mass Spectrom. 1995, 6, 102-113.

36. Lias, S. G.; Bartmess, J. E.; Liebman, J. F.; Holmes, J. L.; Levin, R. D.; Mallard, W. G. Gas-Phase Ion and Neutral Thermochemistry. J. Phys. Chem. Ref. Data 1988, 17, S1-S861(Suppl. 1).

37. Strittmatter, E. F.; Schnier, P. D.; Klassen, J. S.; Williams, E. R. Dissociation Energies of Deoxyribose Nucleotide Dimer Anions Measured Using Blackbody Infrared Radiative Dissociation. J. Am. Soc. Mass Spectrom. 1999, 10, 1095-1104.

38. Monajjemi, M. Chahkandi, B. Theoretical Investigation of Hydrogen Bonding in Watson-Crick, Hoogestein, and Their Reversed and Other Models: Comparison and Analysis for Configurations of AdenineThymine Base Pairs in 9 Models. THEOCHEM J. Mol. Struct. 2005, 714, 43-60.

39. Wang, K.; Schall, O. F.; Gokel, G. W. Detection of Hydrogen-Bonded Adenine-Thymine Base-Pair Complexes by Electrospray Mass Spectrometry. Supramol. Chem. 1996, 9, 85-90. 